Unveiling information on opportunity costs in REDD who obtains the surplus when policy objectives differ?

Delacote, Philip; Palmer, Charles; Bakkegaard, Riyong Kim; Thorsen, Bo Jellesmark

Published in:

Resource and Energy Economics

DOI:

10.1016/j.reseneeco.2013.07.002

Publication date:

2014

Document version

Publisher's PDF, also known as Version of record

Citation for published version (APA):

Delacote, P., Palmer, C., Bakkegaard, R. K., \& Thorsen, B. J. (2014). Unveiling information on opportunity costs in REDD: who obtains the surplus when policy objectives differ? Resource and Energy Economics, 36(2), 508527. https://doi.org/10.1016/j.reseneeco.2013.07.002 


\title{
Unveiling information on opportunity costs in REDD: Who obtains the surplus when policy objectives differ?
}

\author{
Philippe Delacote ${ }^{\mathrm{a}, \mathrm{b}, \mathrm{c}, *}$, Charles Palmer $^{\mathrm{d}}$, \\ Riyong Kim Bakkegaard ${ }^{\mathrm{e}}$, Bo Jellesmark Thorsen $^{\mathrm{f}}$ \\ a INRA, UMR 356 Économie Forestière, F-54000 Nancy, France \\ b Agroparistech, Engref, Laboratoire d'économie forestière, F-54000 Nancy, France \\ c Chaire d'économie du Climat, Paris, France \\ d Department of Geography and Environment, London School of Economics (LSE), Houghton Street, London \\ WC2A 2AE, United Kingdom \\ e Department of Food and Resource Economics, University of Copenhagen, Denmark \\ f Department of Food and Resource Economics, Centre for Macroecology, Evolution and Climate, University \\ of Copenhagen, Denmark
}

\section{A R T I C L E I N F O}

\section{Article history:}

Received 28 February 2012

Received in revised form 1 April 2013

Accepted 6 July 2013

Available online 24 July 2013

\section{JEL classification:}

Q23

$\mathrm{H} 23$

Q54

Q56

\section{Keywords:}

Asymmetric information

Brazil

Deforestation

Opportunity costs

Payments for environmental services REDD

\begin{abstract}
A B S T R A C T
Improving information about individual opportunity costs of deforestation agents has the potential to increase the efficiency of REDD when it takes the form of a payment for environmental services scheme. However, objectives pursued in REDD projects may vary across policy makers. Within a theoretical framework, this paper explores the impacts of different policy objectives under two opportunity cost settings: asymmetric and full information. For a policy maker aiming to maximize net income from REDD, having full information may not increase the amount of forest conserved but could lead to a redistribution of rents away from agents. By contrast, for an environmental policy maker focused on maximizing the amount of forest conserved under REDD having full information increases the amount of forest conserved while reducing the rents received by agents. For a policy maker pursuing poverty alleviation objectives in REDD-affected communities, having full information makes no difference to overall welfare as rents remain with agents. The amount of deforestation avoided will at least be as high as under
\end{abstract}

\footnotetext{
* Corresponding author at: INRA, UMR 356 Économie Forestière, F-54000 Nancy, France. Tel.: +33 383396853.

E-mail address: philippe.delacote@nancy.inra.fr (P. Delacote).
} 
asymmetric information. These results are illustrated with data collected on opportunity costs in Amazonas State, Brazil.

(C) 2013 Elsevier B.V. All rights reserved.

\section{Introduction}

With tropical deforestation accounting for up to a fifth of global, anthropogenic carbon dioxide emissions (van der Werf et al., 2009; IPCC, 1997), Reducing Emissions from Deforestation and Degradation (REDD) has been positioned as a potentially cost-effective climate change mitigation strategy (Stern, 2007; Eliasch, 2008; Engel and Palmer, 2009). Long-term finance is uncertain, although an international carbon market and/or voluntary funds could play a role (see Neeff and Ascui, 2009). Regardless of how finance is sourced for REDD, incentive payments or payments for environmental services (PES) schemes are often emphasized as a key policy tool for internalizing the forest carbon externality (Angelsen, 2010; Pattanayak et al., 2010; Palmer, 2011). ${ }^{1}$ A key selling point is their potential cost-effectiveness compared to other policy options (Ferraro and Kiss, 2002; Ferraro and Simpson, 2002; Muller and Albers, 2004; Groom and Palmer, 2010). Moreover, they are often proposed as efficient policy tools for achieving REDD in developing countries (e.g. Angelsen, 2008; Leplay et al., 2011).

Increased knowledge about the opportunity costs of avoiding deforestation is often cited as a prerequisite for the efficient implementation of payments schemes to curb deforestation (e.g. Pagiola and Bosquet, 2009). Yet as a policy objective, efficiency alone is rarely observed in practice. Instead, such schemes are often implemented with differing and sometimes multiple policy objectives. For example, in many developing countries both environmental and development objectives are often central (see Bulte et al., 2008). In this paper, we investigate the impacts of different policy objectives under two informational settings regarding the opportunity costs of deforestation agents: asymmetric and full information. A simple payments model is developed in which a policy maker offers a price to agents in order to reduce deforestation. The policy maker aims for one of the three types of objectives: maximizing the net income from REDD; maximizing the amount of forest prevented from being deforested in the area; or, alleviating poverty. The last specifically focuses on increasing welfare among agents participating in the scheme. The policy maker can then either sell the carbon credits derived on an international carbon market or it can be retributed through an international REDD fund.

Specifically, we focus on how differing policy objectives may influence forest outcomes and agents' welfare given the information available to the policy maker. Many existing incentive payments schemes, particularly those in developing countries, either have a singular focus on environmental gains or combine this with social or development-led objectives. An example of the former was observed in Los Negros, Bolivia. Facilitated by a local biodiversity NGO and financed by a international conservation agency, compensation to local people was made on a quid-pro-quo basis for protecting biodiversity (Asquith et al., 2008). In addition to environmental objectives, social equity and developmental issues were a key motivation for implementing the Mexican program of payments for Hydrological Environmental Services of Forests (PSAH) Muñoz-Piña et al., 2008. Commonly known as 'co-benefits', biodiversity conservation, good governance and improvements in livelihoods are increasingly being incorporated into REDD payments schemes (UNREDD, 2009; Brown et al., 2008; Simonet et al., 2012). For example, the N'hambita Community Carbon Project in Mozambique promoted carbon sequestration activities alongside improvements in livelihoods (Groom and Palmer, 2012). Although that project did not seek to profit from the sale of carbon offsets, private firms have established numerous forest carbon projects in developing countries (Bayon et al., 2012; Taiyab, 2006).

The policy maker in our framework has one of the three objectives outlined above. It knows the distribution of Business-As-Usual (BAU) levels of deforestation among agents and the distribution of their opportunity costs. Under asymmetric information it cannot infer individual costs. We then explore

\footnotetext{
1 Wunder (2005) defines PES as a voluntary transaction between at least one buyer and at least one seller in which payments are conditional on maintaining an ecosystem use that provides well-defined environmental services.
} 
trade-offs between improvements in agents' welfare and increases in the supply of avoided deforestation benefits from REDD when the policy maker has full information on agents' opportunity costs. A uniform baseline from which payments are made is assumed along with a constant budget size. Yet, policy objectives such as poverty alleviation or environmental improvements can also be achieved through changes in baseline levels and budget constraints. This was shown by Horan and Claassen (2007), who explored the relationship between the efficiency and distributional consequences of payments schemes with limited budgets. Different policy objectives were also a key feature of Wu et al.'s (2001) model of a conservation fund under full information. Although not explicitly considered in our framework, they show how the output price reduces environmental gains from the fund. The extent of change is, at least in part, determined by the targeting strategy adopted by the fund.

Since agricultural households, logging companies, and agri-businesses obtain diverse benefits from deforesting, they can have very different opportunity costs from not deforesting. Thus, some agents can provide environmental services at lower cost than others. Moreover, agents are likely to have better information about the size of these costs than the policy maker. This type of information asymmetry, known as hidden information, can lead to inefficiencies in payments schemes. If the payments exceed agents' opportunity costs then uniform contracts may be a costly way of inducing agents to participate. Yet such payments also have the potential to improve the welfare of scheme participants.

For the purposes of this paper, payments are made to agents when the policy maker either has asymmetric or full information on the opportunity costs of the former. We acknowledge, however, that reality most likely lies between these two settings. To prevent informational rents accruing to low-cost agents, separating contracts can be used to separate the low- from the high-cost agents. ${ }^{2}$ While offering a menu of contracts may be more efficient than a uniform contract, they are rarely used in practice (Ferraro, 2008). ${ }^{3}$ Informational requirements on the part of the policy maker may be substantial and the menu of contracts that would be offered in the presence of complete information may not be incentive compatible in the presence of information asymmetries (Arguedas and Soest, 2011). Instead of offering a menu of contracts, procurement auctions have been proposed and used in practice as a means of extracting informational rents from agents (e.g. Stoneham et al., 2003; Jack et al., 2009). Note also that while, for example, 'first rejected bid sets the price' auctions may be incentive compatible, incentive compatibility may nevertheless depend on allowing low-cost agents some rent, i.e. not all rents may be extracted. Thus, improving information on agents' opportunity costs is possible, although debate continues about the relative efficiency of separating contracts vis-a-vis auctions.

We introduce the model, beginning with the asymmetric information setting, in Section 2 . The three types of policy maker set the same level of REDD payment resulting in the same environmental outcome. Section 3 presents the setting in which policy makers have full information about agents' opportunity costs. Both the welfare and avoided deforestation outcomes depend on the policy maker's objective. If maximizing income from REDD, having full information allows the policy maker to bind agents to their opportunity costs. It is then able to capture the surplus rents. Thus, the well-being of agents is reduced but with no change in the amount of avoided deforestation relative to the asymmetric information setting. With an environmental objective, improving information improves scheme effectiveness in terms of avoided deforestation. Less money is spent on agents with low opportunity costs and more is allocated to those with higher costs, i.e. agents lose the rents associated with asymmetric information. In this case, improving information increases the outcome in terms of avoided deforestation but leaves agents with no net welfare gain. When the main aim is poverty alleviation, improving information will have no impact on the overall welfare outcome as rents stay with agents. Under reasonable assumptions, outcomes may also remain unchanged under full information. More generally, the distribution of rents across agents may depend on the policy maker's preferences, resulting in avoided deforestation outcomes that are at least as high as under asymmetric information but always below the outcome when the main aim is reducing deforestation.

\footnotetext{
2 For classic examples of separating contracts as applied to agri-environmental schemes, see Smith (1995) and Wu and Babcock $(1995,1996)$.

3 Payments have, however, been reported to be differentiated according to scheme-specific criteria such as agro-ecological zones in order to meet environmental objectives (Wunder et al., 2008). Schemes in both Bolivia and Ecuador, for example, offered payments, which were differentiated according to the types of forest held by landowners and farmers.
} 
These results are illustrated with data collected on households' opportunity costs in the Brazilian state of Amazonas, in Section 4. Land use is characterized by low productivity agriculture on land made available through the conversion of forest of high carbon content. Under a hypothetical REDD payments scheme, and with full information on opportunity costs, a policy maker with an environmental objective is able to enrol almost all of the forest in the area. Less forest is enroled by a policy maker with either of the other two policy objectives. The data could allow for second-order discrimination among potential scheme participants. However, relatively little variation in opportunity costs is observed among most agents in our sample thus implying few informational rents. Section 5 discusses the results along with their policy implications before concluding.

\section{Payments for reducing deforestation under asymmetric information}

In this section, we present an incentive payments scheme for reducing emissions from deforestation when there is asymmetric information on deforestation agents' opportunity costs of avoiding deforestation. We first present the deforestation agents and the Business-As-Usual (BAU) deforestation baseline before moving to the payments scheme. As in Leplay et al. (2011), several types of policy maker objectives are considered and the equilibrium payments policy is inferred.

\subsection{Deforestation agents and Business-As-Usual scenario}

We consider a potential REDD host country in which deforestation agents, e.g. agricultural households, logging firms, $i \in[0, N]$, are distributed according to $f(i)$. The deforestation agents obtain some private benefit (or net income) $Y_{i} \in[\underline{Y}, \bar{Y}]$ from deforestation $D_{i} \in[\underline{D}, \bar{D}]$.

In our model, $D_{i}$ is the individual deforestation level of agent $i$, and $D^{\mathrm{BAU}}=\int_{0}^{N} D_{i} f(i) d i$ is the total level of deforestation in a BAU scenario. Moreover, agent $i$ obtains private benefits $Y_{i}$ from deforestation $D_{i}$, which are assumed to be known by the agent. Total benefits from deforestation are given by $Y^{\mathrm{BAU}}=$ $\int_{0}^{N} Y_{i} f(i) d i$ in a BAU scenario, which can also be interpreted as an aggregate measure of deforestation agents' welfare.

We assume that the policy maker has information on the distribution of deforestation levels and agents' opportunity costs, and also on individual agents' deforestation levels. The information asymmetry thus only holds on individual opportunity costs. We justify this assumption on the basis of there typically being wide variation in $Y_{i}$ for a given $D_{i}$ across agents. In other words, individual agents have private information regarding the profitability of their deforestation activities, which will depend on, for example, their labor endowments, social capital and degree of market access. ${ }^{4}$

\subsection{Introducing payments for reducing emissions from deforestation}

The policy maker in the REDD host country establishes an incentive payments or PES scheme to reduce emissions from deforestation. In response to the information asymmetry, it offers fixed, uniform payments per hectare as an incentive to avoid deforestation against the BAU baseline.

Any agent $i$ may accept or refuse the offer. If it accepts, agent $i$ reduces its deforestation from $D_{i}$, the payment baseline, to $D_{i}^{\mathrm{PES}}$. For simplicity, we assume that $D_{i}^{\mathrm{PES}}=0$. In this sense, we consider $D^{\mathrm{BAU}}$ as the quantity of deforestation that is avoided, or similarly, we assume zero variation in the opportunity costs of individual agents, i.e. across their land holdings. We assume perfect monitoring of deforestation levels under the payments scheme, for example, using a combination of remote sensing data and ground surveys. This could form part of the monitoring, measurement and verification (MRV) procedures established in the REDD host country. Such monitoring thus precludes problems of moral hazard and contract compliance on the part of agents. In exchange for avoiding deforestation the agent

\footnotetext{
${ }^{4}$ However, our qualitative results also hold when individual deforestation levels are not known by the policy maker, if individual levels of deforestation are positively related to opportunity costs. The only difference is that the uniform payment is not made per hectare of avoided deforestation but as a fixed amount.
} 
receives a fixed payment per hectare $p$. If it declines participation in the scheme, agent $i$ continues to receive its BAU income $Y_{i}$. Agent $i$ accepts the offer if and only if it makes it better off: $p D_{i} \geq Y_{i}$.

In our framework, third-party finance for REDD can be accessed by the policy maker based on the REDD host country. Since payments for avoided deforestation are made conditional on the provision of the forest carbon service, we assume secure land tenure and well-defined property rights. Although these conditions are fundamental to the effectiveness of REDD, we note that tenure reform has been lagging in the majority of REDD-eligible countries (Sunderlin et al., 2009). There are two options for channeling REDD finance. First, verifiable avoided deforestation could create carbon (offset) credits, which can then be sold on an international carbon market at price $r$. Alternatively, the policy maker could be retributed through an international REDD fund established by developed countries. In this case, $r$ would represent the price offered by the fund in exchange for a given, verified amount of avoided deforestation.

\subsection{The policy maker}

In our framework, the indifferent agent $\tilde{1}$ is the one who separates the total population, and is defined as: $\tilde{Y}=p \tilde{D}$. Agents with a low opportunity cost $(i \in[0, \tilde{1}])$ participate in the scheme while agents with a high opportunity cost $(i \in[\tilde{1}, N])$ choose to stay out.

Total agent income, total deforestation levels under the payments scheme, avoided deforestation and the cost of the payments scheme are given by:

$$
\begin{aligned}
& Y^{\mathrm{PES}}=\int_{\tilde{\mathrm{I}}}^{N} Y_{i} f(i) d i+\int_{0}^{\tilde{1}} p D_{i} f(i) d i \\
& D^{\mathrm{PES}}=\int_{\tilde{\mathrm{I}}}^{N} D_{i} f(i) d i \\
& A D=D^{\mathrm{BAU}}-D^{\mathrm{PES}}=\int_{0}^{\tilde{1}} D_{i} f(i) d i \\
& C=\int_{0}^{\tilde{\mathrm{I}}} p D_{i} f(i) d i
\end{aligned}
$$

Under asymmetric information, the policy maker only has to set the amount of the payment $p$, which determines the indifferent agent and the number of agents entering the scheme $i \in[0, \tilde{1}]$. It cannot discriminate among deforestation agents, and therefore cannot capture the surplus rents from the REDD scheme. Participants are assumed to comply and deliver the benefits associated with their REDD contracts. As noted previously, there is perfect and costless monitoring of REDD contracts.

The policy maker has one of the three types of objectives. First, we consider a policy maker that aims to maximize net income from REDD, before considering one aiming to maximize the size of the forest of the area to be protected under REDD. Finally, the policy maker has a poverty alleviation objective that aims to maximize the welfare of agents participating in the REDD scheme.

\subsubsection{Policy maker aiming to maximize net income}

As described in Section 1, the objective of maximizing net income from REDD can be interpreted in different ways. First, it may characterize the profit-driven objectives of private sector intermediaries and project developers, which establish forest carbon projects in response to the demand for voluntary offsets. Second, it could be a government that prefers to increase social welfare by utilizing the income obtained from REDD rather than distributing it to deforestation agents. Thus, income from REDD could be used to fund public services such as education, health, and infrastructure, or could be distributed to the population at large. The latter could apply in a situation where the social cost of public funds is small enough, i.e. implying that the policy maker can improve social welfare using REDD finance for public services rather than directly distributing it to agents. Third, it could 
be a corrupt government that distributes income to rent-seeking groups through its client-patron networks. ${ }^{5}$

The maximization program of the policy maker is:

$$
\max _{p} \pi_{P M}=r A D-C
$$

2.3.2. Policy maker aiming to maximize the environmental impact

In our second case, the policy maker has the objective of maximizing the quantity of avoided deforestation. Its program is:

$$
\begin{aligned}
& \max _{p} A D=D^{\mathrm{BAU}}-D^{\mathrm{PES}} \\
& \text { s.t. } r A D-C \geq 0
\end{aligned}
$$

\subsubsection{Policy maker aiming to alleviate poverty}

The last type of policy objective only focuses on the welfare of deforestation agents. The policy maker thus implements its payments scheme such that the welfare of deforestation agents is maximized compared to the BAU baseline subject to a budget constraint, i.e. it cannot make a loss from implementing the scheme:

$$
\begin{aligned}
& \max _{p} W_{A}=Y^{\mathrm{PES}}-Y^{\mathrm{BAU}} \\
& \text { s.t. } r A D-C \geq 0
\end{aligned}
$$

\subsubsection{Summarizing the solution across objectives}

In all three cases, asymmetric information implies that the policy maker implements the same payment level across agents. Indeed, since the policy maker cannot discriminate among deforestation agents, the surplus from REDD remains with the agents. Asymmetric information about agents' opportunity costs prevents the policy maker from being able to redistribute the surplus from REDD. Note that agents are better off under asymmetric information, i.e. they benefit from holding private information about their opportunity costs, which increases their welfare relative to the BAU baseline.

The equilibrium payments scheme thus takes the form:

$$
\left\{\begin{array}{l}
p=r \forall i \in[0, N] \\
\tilde{\imath}: \frac{\tilde{Y}}{\tilde{D}}=r
\end{array}\right.
$$

Fig. $1^{6}$ presents the outcomes of payments made for the three policy objectives under asymmetric information. Fig. 1i presents the distribution of average opportunity costs $Y_{i} / D_{i}$; Fig. 1ii presents the distribution of opportunity costs $Y_{i}$; Fig. 1iii presents the distribution of deforestation levels $D_{i}$. Due to asymmetric information about individual opportunity costs, the policy maker sets the same payment level irrespective of its objective. A uniform payment is implemented and deforestation agents decide whether or not to enter into the scheme.

The policy maker sets $p=r$ (Fig. $1 \mathrm{i}$ ), with the indifferent agent represented by $\tilde{Y}_{B, P, E} / \tilde{D}_{B, P, E}=r$. Deforestation agents increase their welfare relative to the BAU baseline by the amount shown in zone 1 in Fig. 1ii. While they receive $p D_{i}$ for not deforesting, they generate $Y_{i}<p D_{i}$ for deforesting. The amount of deforestation avoided is shown in zone 2 of Fig. 1iii. Finally, the REDD payments scheme

\footnotetext{
5 Therefore, we do not consider explicitly how the net income from REDD is used, whether it is in a positive (public services) or negative (rent-seeking) way.

${ }^{6}$ To simplify the presentation of the figures, we implicitly assume here that agents with low opportunity costs also have low levels of deforestation.
} 




Fig. 1. Payments scheme for REDD under asymmetric information.

binds the budget constraint since the payment $p \tilde{D}_{B, P, E}$ is sold at $r \tilde{D}_{B, P, E}$ to the carbon buyer participating either in the international carbon market or the REDD fund.

\section{The impact of making payments under full information}

In this section, we consider the impact of payments on deforestation avoided and agents' welfare when the policy maker has full information about agents' opportunity costs. Since full information is the polar opposite of asymmetric information, reality will most likely be a case of improved information. Such improved information may be derived from procurement auctions of conservation 
contracts in the targeted areas. This is provided they are designed to be incentive compatible thus prompting agents to reveal their true opportunity costs. Alternatively, screening contracts could be used to reduce the capture of informational rents by landowners. Yet, we note that these require knowledge of landowner types and therefore may be costly for policy makers to implement (see Ferraro, 2008). Finally, information may be derived from household income surveys linking deforestation income to agent observables, as illustrated for the case of Amazonas state, in Section 4.

As a result, the policy maker can infer information about agents and payments may be implemented in a more flexible way. More precisely, the policy maker is able to discriminate agents according to their opportunity costs. The payment now consists of an agent specific price $p_{i}$ to the deforestation agent $i$ per hectare of avoided deforestation. The indifferent agent $\tilde{\tilde{I}}$ is the one who separates the total population, and is defined as: $\tilde{\tilde{Y}}=\tilde{\tilde{p}} \tilde{\tilde{D}}$. Agents with a low opportunity cost $(i \in[0, \tilde{\tilde{i}}])$ participate in the scheme while agents with a high one $(i \in[\tilde{\tilde{i}}, N])$ opt out. The only difference, compared to the previous model, is that $p$ becomes $p_{i}$ in Eqs. (1) and (4).

When setting the price schedule $p_{i}$ of the scheme, the policy maker has to make two choices. First, it chooses the indifferent agent $\tilde{\tilde{1}}$, i.e. the final or last agent to participate in the scheme, setting $p_{\tilde{\mathrm{I}}}$. Second, it decides how much to pay agents entering the scheme, setting $p_{i}$ for agents $i \in[0, \tilde{\tilde{1}}]$.

The choice of the indifferent agent determines the quantity of avoided deforestation, $A D$. The price level determines how the surplus from REDD is distributed between the policy maker and deforestation agents. Setting $p_{i}=Y_{i} / D_{i}$ implies that agents are retributed according to their opportunity costs, which means that the surplus from REDD is entirely captured by the policy maker. In other words, agents' welfare remains as in the BAU baseline case. Setting $p_{i}>Y_{i} / D_{i}$ implies that some share of the REDD surplus is distributed to deforestation agents. Thus, they are better off under the scheme compared to the BAU baseline case.

\subsection{Policy maker aiming to maximize net income}

The policy maker aiming to maximize net income will pay deforestation agents so long as it makes profit on the scheme. Note that the price offered must remain lower than the international price $r$. Moreover, it will pay them as little as possible. In the context of improved information about agents' opportunity costs, this means that it will bind them to these costs.

The equilibrium scheme is thus:

$$
\left\{\begin{array}{l}
p_{i}=\left\{\begin{array}{l}
\frac{Y_{i}}{D_{i}} \forall i \in[0, \tilde{\tilde{1}}] \\
r \forall i \in[\tilde{\tilde{1}}, N]
\end{array}\right. \\
\tilde{\tilde{1}}: \frac{\tilde{\tilde{Y}}}{\tilde{\tilde{D}}}=r \\
\int_{0}^{\tilde{\tilde{1}}}\left(r-p_{i}\right) D_{i} f(i) d i>0
\end{array}\right.
$$

Compared to the asymmetric information setting, the policy maker with full information can bind agents to their opportunity costs, which implies a different distribution of the surplus from REDD. Deforestation agents' welfare is then exactly the same as in the BAU baseline and lower than that found under asymmetric information.

\subsection{Policy maker aiming to maximize the environmental impact}

In contrast to the previous policy objective, the policy maker with an environmental aim could potentially offer a price higher than the international carbon price to some agents. Indeed, it prefers to make some profit on agents with a low opportunity cost by paying them a price lower than the international price. This profit can then be used to give incentives to agents with a high opportunity cost. The policy maker thus binds agents to their opportunity costs. 
Overall, the equilibrium payments scheme takes the form:

$$
\left\{\begin{array}{c}
p_{i}=\left\{\begin{array}{l}
\frac{Y_{i}}{D_{i}} \quad \forall i \in[0, \tilde{\tilde{1}}] \\
r \quad \forall i \in[\tilde{\tilde{1}}, N]
\end{array}\right. \\
\tilde{\tilde{1}}: \int_{0}^{\tilde{\tilde{I}}}\left(r-p_{i}\right) D_{i} f(i) d i=0
\end{array}\right.
$$

In this case, making a profit on some deforestation agents enables the policy maker to pay agents with opportunity costs more than the international carbon price. Thus, the quantity of avoided deforestation is higher than the quantity achieved with the income-maximizing policy maker. Deforestation agents' welfare, however, is the same as in the BAU case and strictly lower than under asymmetric information.

\subsection{Policy maker aiming to alleviate poverty}

Where the policy maker aims at maximizing the welfare of agents involved in the REDD scheme, its preference is to allow the agents to keep the REDD budget provided the budget constraint is binding. However, the distribution of the rent can take any form, depending on the policy maker's preferences. That is, it depends on the relative weight placed on respective agents' rent gains.

To illustrate, we assume that the policy maker prefers to follow Rawls' criterion (1971). Thus, it maximizes the welfare of the least-favored deforestation agent ex post, i.e. after the REDD payment has been made. In this case, provided the agents' opportunity costs $Y_{i} / D_{i}$ exactly reflect the relevant welfare ordering, there is a unique solution to Eq. (7). Indeed, a uniform payment to participating agents is required by the maximin objective, where $r$ is the maximum amount of money the policy maker can give to every agent involved without making a loss. Therefore, so long as the offered price $p_{i}$ is strictly larger than agent $i$ 's opportunity cost, $i$ will be better off under the scheme.

The equilibrium payments scheme thus takes the form:

$$
\left\{\begin{array}{l}
p_{i}=r \quad \forall i \in[0, N] \\
\tilde{\tilde{1}}: \frac{\tilde{\tilde{Y}}}{\tilde{\tilde{D}}}=r \\
\int_{0}^{\tilde{\tilde{1}}}\left(r-p_{i}\right) D_{i} f(i) d i=0
\end{array}\right.
$$

The policy maker sets a uniform price to all agents, which is similar to that set under asymmetric information. Low opportunity cost agents accept the payment, which improves their well being. They lose $Y_{i}$ but get $r D_{i}>Y_{i}$. The policy maker then sells the avoided deforestation credits at the same price $r$, and is thus able to finance the policy without loss. Note here that agents with a high opportunity cost obtain the same welfare as in the BAU baseline.

It can be seen that under these assumptions, the indifferent agent is the same as found under asymmetric information. The outcome in terms of avoided deforestation is also the same, as is the adoption of a uniform payment or price to avoid deforestation. Thus, when the policy maker opts to alleviate poverty through the adoption of the Rawlsian maximin criterion, $p_{i}=r$. Under full information, both agents' welfare and the quantity of avoided deforestation are identical to the outcomes achieved under asymmetric information. Improving information about agents' true opportunity costs therefore has no real impact on either outcome.

However, there may be other ways of distributing the rent if we relax the assumption of ordering according to $\mathrm{Yi} / \mathrm{Di}$. In this case, the implemented REDD scheme would depend on an explicit model of distribution that has to be specified. In other words, what weight is given by the policy maker to agents with a low opportunity cost? Fig. 2 shows that depending on the preferred transfer profile, one could use the budget to offer non-uniform payments to agents. The red and green dashed lines represent two possibilities for distribution of the rent to agents. This could result in a continuum of avoided 


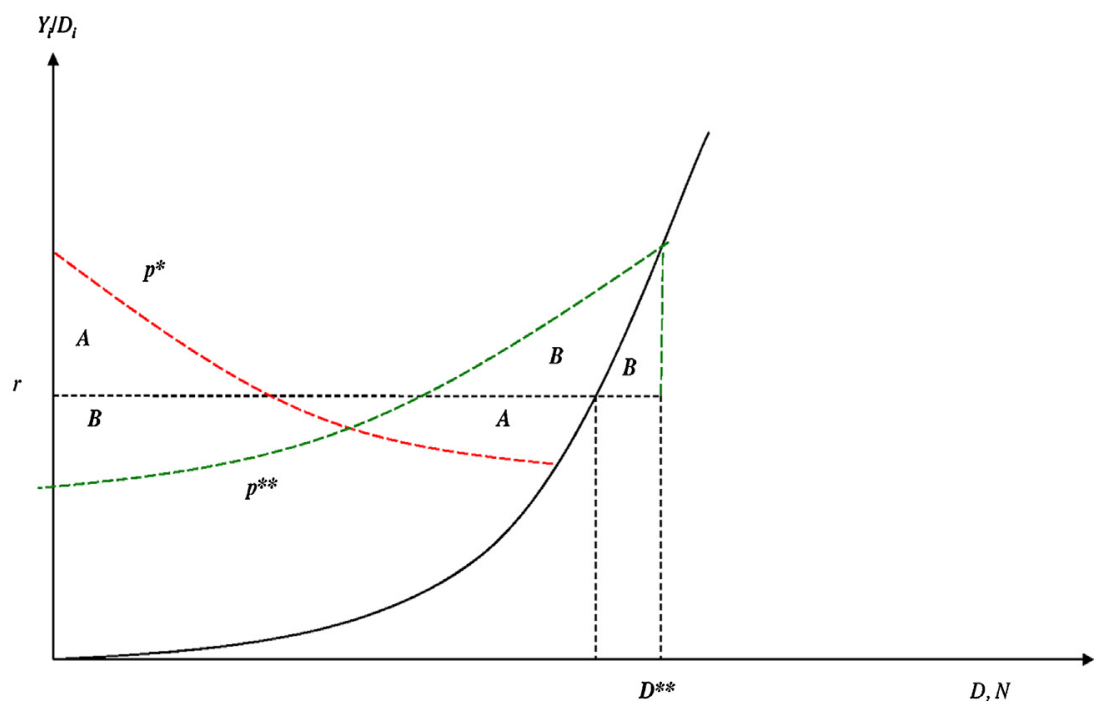

Fig. 2. Different transfer profiles for the policy maker aiming to alleviate poverty.

deforestation amounts as well. The budget constraint will be fulfilled provided $A$ above $r$ equals $A$ below $r$, likewise for the $B$ areas.

By implication, the policy maker with a poverty alleviation objective will always have aggregate output equal to or above that of the income maximizer and below or equal to that of one focused on the environment. It will never have aggregate $D$ below the income maximizer because that would mean forgoing additional funds to enhance agents' welfare, which runs counter to its poverty alleviation objective. Further, it cannot set a price resulting in an aggregate level of avoided deforestation higher than that of the environmental policy maker since that would mean not making any agent better off at all. This is also counter to the poverty alleviation objective. Regardless of the aggregate $D$, the aggregate welfare gain can never rise above that of the case where $p_{i}=r$ for all $i$, because the aggregate surplus to be distributed is maximized at this level.

In sum, the outcomes of these many possible $p_{i}$ schemes are: (i) the agents obtain the same total welfare gain in all cases; (ii) the forest secured would be equal to or larger than the amount of forest secured under income-maximization but never larger than the area secured under the environmental policy objective. Finally, the use of the uniform payment $p_{i}=r$ as the method of transferring rents and improving welfare may also be preferable for practical and cost reasons. Payments schemes in practice rarely implement price discrimination based solely on criteria related to poverty such as the ones described above. Instead, most targeting is based on ratios of benefits, risks and/or costs, even in schemes that incorporate equity co-benefits as an additional objective (e.g. Muñoz-Piña et al., 2008).

Proposition 1. When implementing a payments scheme with the option of selling the benefits from avoided deforestation to a REDD fund or international carbon market and with full information about agents' opportunity costs and deforestation levels, the policy maker aiming to maximize its income obtains the lowest level of avoided deforestation while the policy maker aiming to maximize the amount of deforestation avoided achieves the highest level. The policy maker pursuing poverty alleviation in the REDD-affected community will obtain at least the same REDD outcome as the income-maximizing policy maker, and never more than the environmental policy maker. Regarding welfare, the policy maker aiming to alleviate poverty increases deforestation agents' welfare with payments while the income-maximizing and environmental policy makers bind deforestation agents to their opportunity costs, which prevents them from being better off under REDD. 
Table 1

Outcomes under full information.

\begin{tabular}{|c|c|c|c|c|}
\hline & Indifferent agent, ĩ & $\begin{array}{l}\text { Agents' welfare, } \\
W_{A}\end{array}$ & $\begin{array}{l}\text { REDD net } \\
\text { income, } \pi_{P M}\end{array}$ & $\begin{array}{l}\text { Avoided } \\
\text { deforestation, } A D\end{array}$ \\
\hline Poverty alleviation & $\tilde{\tilde{\mathbf{l}}}_{B P}$ & 1 & 0 & 3 \\
\hline Income maximization & $\tilde{\tilde{\mathbf{l}}}_{B P}$ & 0 & 1 & 3 \\
\hline Environment & $\tilde{\tilde{\mathrm{i}}}_{E}$ & 0 & $1-2=0$ & $3+4$ \\
\hline
\end{tabular}

Proposition 2. In comparison to the asymmetric information scenario, when improving information about individual opportunity costs:

- Under a income-maximization objective, the policy maker can profit from low opportunity cost agents, which results in the same avoided deforestation outcome while the surplus from REDD is switched from the deforestation agents to the policy maker.

- Under an environmental objective, the policy maker redistributes REDD rent from low opportunity cost agents to agents with higher opportunity costs; the amount of deforestation avoided is larger while the welfare of deforestation agents decreases.

- Under a poverty alleviation objective, the policy maker could implement an infinity of schemes depending on its preferred transfer profile. When it applies Rawls? criterion, it sets the same level of payment. This results in the same outcome both in terms of avoided deforestation and welfare. When not applying Rawls, other solutions for pi imply that the aggregate welfare for agents remains the same as with no information but the distribution changes. The REDD outcome, however, will be intermediate compared to the outcome under the other two policy objectives.

\subsection{Graphic illustration}

Table 1 and Fig. 3 illustrate the payments schemes and associated outcomes for the three policy objectives under full information. Similar to Fig. 1, Fig. 3i presents the distribution of average opportunity costs $Y_{i} / D_{i}$; Fig. 3ii, the distribution of opportunity costs $Y_{i}$; Fig. 3iii, the distribution of deforestation levels $D_{i}$.

The policy maker can now discriminate among deforestation agents. Under an incomemaximization objective, the policy maker sets $p_{i}=Y_{i} / D_{i}$, up to $p_{i}=r$ (Fig. $3 \mathrm{i}$ ). As a consequence, the indifferent agent remains $\tilde{\tilde{I}}_{B, P}$, although the agents' welfare is the same as under BAU. Avoided deforestation is still equal to zone 3, in Fig. 3iii. However, the scheme makes some profit as illustrated in zone 1 (Fig. 3ii). The policy maker buys avoided deforestation at price $Y_{i} / D_{i}$ and sells the credit at price $r>Y_{i} / D_{i}$.

Under an environmental objective, the policy maker also makes some profit on low opportunity cost agents (zone 1 in Fig. 3ii). This profit is redistributed to agents with higher opportunity costs. The indifferent agent here is $\tilde{\tilde{I}}_{E}$ such that the area in zone 1 equals the area in zone 2 (Fig. 3ii), that is the scheme makes no profit. A larger number of indifferent agents increase the amount of avoided deforestation equivalent to both zone $3+4$ (Fig. 3iii).

Finally, under a poverty alleviation objective, the policy maker following the Rawlsian criterion sets $p_{i}=r$ for all agents (Fig. $3 \mathrm{i}$ ). As a result, the indifferent agent is $\tilde{\mathbf{i}}_{B, P}$. Their welfare increases by the amount given in zone 1 (Fig. 3ii). This is the difference between the amount received under the scheme and the amount received in the BAU baseline $\left(r D_{i}-Y_{i}\right)$. The amount of deforestation avoided is illustrated in zone 3, in Fig. 3iii. The scheme breaks even since the amount spent $\left(p_{i} \tilde{\tilde{D}}_{B, P}\right)$ equals the amount received from international REDD finance $(r A D)$, as shown in zone 1 (Fig. 3ii). Note that other avoided deforestation outcomes are possible for the policy maker with a poverty focus, although these are bounded by those of the other policy objectives. 

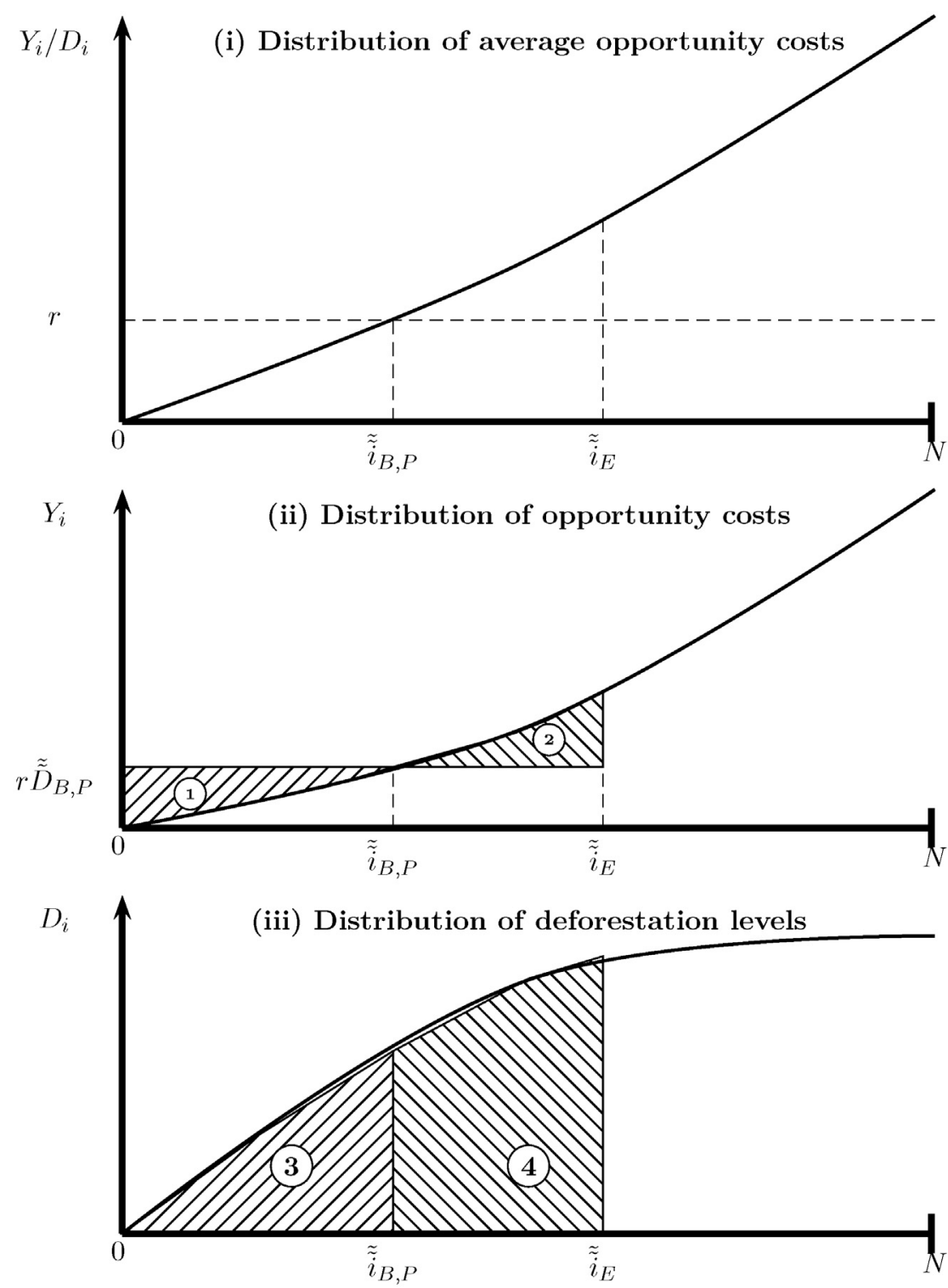

Fig. 3. Payment scheme and avoided deforestation under full information.

\section{Model simulations using Brazilian data}

\subsection{Case study presentation}

Brazil is a priority for REDD activities. The country hosts two-thirds of the world's largest forest, the Amazon biome, which covers 6.4 million square kilometers. This contains the equivalent of 15 years of current annual worldwide anthropogenic emissions (Soares-Filho et al., 2006; May et al., 2011). Absolute deforestation rates in Brazil are also among the highest in the world, representing approximately one-fifth of global $\mathrm{CO}_{2}$ emissions from land-use change (Börner et al., 2010). In recent 


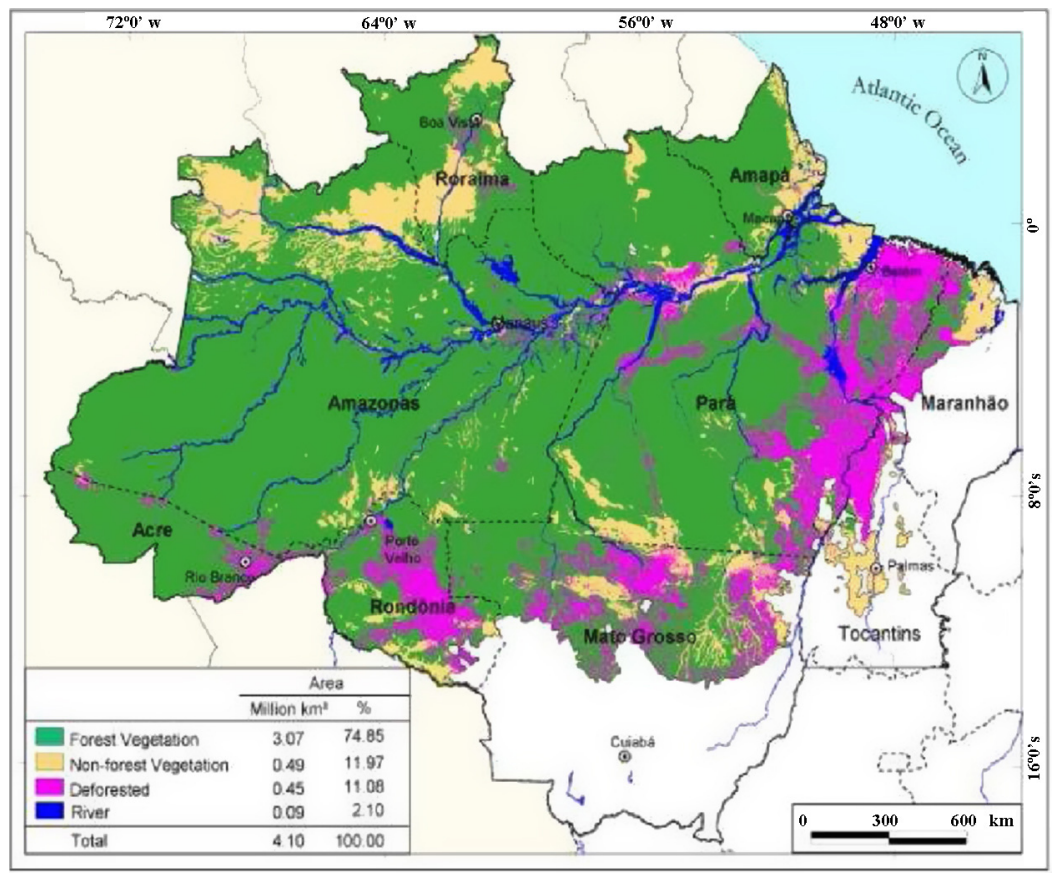

Fig. 4. Forest vegetation and deforestation in the Brazilian Amazon, 2001.

Source: http://www.globalforestwatch.org. The baseline for the Human Pressure analysis was a dataset that combines vegetation (IBGE, 1997) and deforestation as of 2001 (INPE 2003).

decades, frontier expansion has occurred along the 'Arc of Deforestation', which stretches from the northeast of the states of Para, Tocantins, Maranhão, down to Mato Grosso and west to Rondônia, ending in the state of Acre (Fig. 4). New frontiers have recently begun to emerge, including the southern border of Amazonas state (May et al., 2011).

The state of Amazonas is one of the 10 states comprising the Legal Amazon (Amazonia Legal), covering 61 percent of the country. Households in all areas not designated as reserves are bound by the Brazilian Forest Code, which, during the study period, required at least 80 percent of their land to be under forest cover. Surveyed households were randomly chosen from a selection of villages both inside and outside two state-level protected areas or reserves, Uatumã and Juma. The simulations utilized data collected from 96 households outside the two reserves (50 outside Uatumã and 46 outside Juma), and not those surveyed inside the reserves. This is to avoid confounding the simulation results through the use of data from households who were already receiving incentive payments for conservation and were subject to tighter restrictions on land use inside the reserves.

\subsection{Estimation of opportunity costs and BAU deforestation}

Opportunity costs are estimated from the household survey, which included information on household income earned and assets held in the year prior to the survey. Socio-demographic data such as household composition, age, and education were collected as well as data on land clearing, extraction behavior and household well-being. The average shares of annual income by source at the aggregate, sample level are shown in Table 2. They highlight the general importance of livestock and agricultural incomes to households in the study areas.

Outside Juma, the predominant income source and land-use activity is livestock (mainly cattle) while agriculture (cassava and fruits) dominates outside Uatumã. Opportunity costs per hectare of forest land are first calculated using agriculture and livestock income at the household level since 
Table 2

Average annual income shares for sampled households outside the reserves.

\begin{tabular}{lllllll}
\hline & \multicolumn{2}{l}{ Non natural resource-based income } & & \multicolumn{2}{l}{ Natural resource-based income } \\
\cline { 5 - 7 } Total income shares & Business & Salary & Other & Forest & Net agriculture & Net livestock \\
\hline Outside Juma & 0.06 & 0.20 & 0.15 & 0.12 & 0.17 & 0.29 \\
Outside Uatumã & 0.02 & 0.14 & 0.15 & 0.23 & 0.33 & 0.11 \\
\hline
\end{tabular}

Table 3

Descriptive statistics for households outside the reserves.

\begin{tabular}{|c|c|c|c|c|}
\hline & $N$ & Mean & S.D. & Min \\
\hline \multicolumn{5}{|l|}{ Net productivity ${ }^{\mathrm{a}}$ (BRL/ha) } \\
\hline Low estimate & 91 & 1396.10 & 2229.88 & -289 \\
\hline Net agricultural income (BRL) & 85 & 5950.66 & 9739.77 & -4800 \\
\hline Net livestock and animal product income (BRL) & 76 & 4996.94 & 13659.78 & -13167 \\
\hline Land use over past 4 years (ha) & 96 & 29.52 & 65.76 & 0 \\
\hline Total cropland (ha) & 92 & 2.25 & 3.35 & 0 \\
\hline Total pasture (ha) & 92 & 23.93 & 56.59 & 0 \\
\hline Early fallow (ha) & 92 & 4.61 & 13.45 & 0 \\
\hline
\end{tabular}

${ }^{\text {a }}$ Net productivity is defined as: agricultural livestock/animal income per hectare of cropland + pasture + early fallow.

they are the primary land uses after forest is cleared in the area (SDS et al., 2010). This is then divided by the sum of land currently under cropland or pasture as well as early fallow in order to obtain $Y_{i} / D_{i}$.

However, while all of this area is in production it does not correspond to a single year of deforestation behavior at the household level. To account for the periodicity of agriculture, we estimated an annual land clearance figure $\left(D_{i}\right)$ by dividing the sum of cropland, pasture and early fallow by ten years. According to Vosti et al. (2002), agricultural production (annual crops) in the Amazon is generally viable for two years after which fields are left to fallow for around three years before fields are planted again. Alternatively, fields can be converted to pasture, which are viable for 15 years. In our measure of net agricultural and livestock productivity per hectare on current land in production and recently fallowed land, we assume a static income flow and ignore the diminishing returns to land over time as a result of decreasing soil and land productivity.

The aggregate productivity of 1 ha was estimated for each household by dividing the net income derived from agriculture and livestock and animal product sources by the total land dedicated to each of these activities (cropland, pasture and early fallow).

Summary statistics of net productivity in Brazilian Reais (BRL) are presented in Table 3, showing the value per hectare of cropland, pasture and early fallow. ${ }^{7}$ Mean incomes are also provided in BRL. These also vary widely among individual households. Due to the difficulties in getting respondents to discriminate between inputs and investment, a snap-shot measurement like this will have some households report negative incomes, e.g. as a result of one-off, substantial purchases of inputs, or investments. The mean area under cropland is much smaller than the area under pasture. Thus, income per hectare is on average much higher for agriculture than for livestock, the latter being an extensive but land-intensive activity.

\subsection{Setting a carbon payment level}

In order to generate a feasible international payment for avoiding deforestation $(r)$, several factors need to be considered. First, a carbon price has to be determined. Assuming that REDD markets are

\footnotetext{
7 One household claimed a total area of land, which seemed unreasonably small for the amount of agricultural production, and is therefore excluded from the sample. Another four households who either had no recorded agricultural or livestock income, or recorded land were also excluded.
} 


\section{Table 4}

Discount rate and corresponding payments.

\begin{tabular}{llll} 
Discount rate, $\rho$ & $5 \%$ & $10 \%$ & $15 \%$ \\
Price of permanent $\mathrm{CER}, € / \mathrm{tCO}_{2}$ & 10 & 10 & 10 \\
Price of 5-year non-permanent tCER, $€ / \mathrm{tCO} 2$ & 2.16 & 3.79 & 5.03 \\
Annual payment, $€ / \mathrm{tCO}$ & 0.48 & 0.95 & 1.43 \\
Annual payment, $\mathrm{BRL} / \mathrm{tCO} 2$ & 1.10 & 2.19 & 3.29 \\
Annual payment, $\mathrm{BRL} / \mathrm{ha}=r$ & 442 & 883 & 1325 \\
\hline
\end{tabular}

based on the sale of temporary credits (Börner and Wunder, 2008), we opted to use the crediting structure as adopted by afforestation and reforestation projects in the Clean Development Mechanism (CDM). These projects allocate temporary Certified Emissions Reductions (tCERs), which typically fetch a price lower than that of permanent CERs. A conservative estimate of $10 € / \mathrm{tCO}_{2}$ for permanent CERs is used. Second, a discount rate is chosen that will affect the value of tCERs against permanent CERs. We opted to vary the discount rate between 5 and 15 percent, as seen in Table 3 . This range is chosen in order to show the sensitivity of the simulation results to changes in the tCER price. Given the higher risks a carbon market may associate with carbon credits from REDD compared to other mitigation options, the lower bound is set relatively high at five percent. The relationship between the price of a tCER, $P_{0}^{\mathrm{tCER}}$, and that of a permanent CER, $P_{0}^{\mathrm{CER}}$, is given by (see Dutschke et al., 2004):

$$
P_{0}^{\mathrm{tCER}}=P_{0}^{\mathrm{CER}}-\frac{P_{T}^{\mathrm{CER}}}{(1+\rho)^{T}}
$$

where $\rho$ is the discount rate and $T=5$. We convert this price into the corresponding annuity over the five years before applying it to the eligible amount of $\mathrm{CO}_{2}$ per hectare (see below and Table 4). This enables a comparison with our estimates of annual per hectare opportunity costs.

Carbon content per hectare varies widely in the Amazon. We apply a conservative estimate of $110 \mathrm{Mg} \mathrm{C} /$ ha, corresponding to $403 \mathrm{tCO}_{2}$ /ha (Houghton, 2001). In the calculations shown below, we present payments for net carbon stock, of around $81.5 \mathrm{t} \mathrm{C/ha} \mathrm{(equivalent} \mathrm{to} \mathrm{around} 75 \%$ of gross stocking per ha) ${ }^{8}$

\subsection{Simulation results}

Fig. 5 identifies the total and marginal hectare purchased under the REDD payments scheme, at each level of $r$ and for the alternative cost estimations. The $x$-axis shows the distribution of land, which is ordered by households' increasing opportunity cost per hectare deforested. The $y$-axis shows the price $r$ and the annual opportunity cost per hectare. High-cost hectares were truncated in this figure as they are very few and very expensive. Nonetheless, they are included in the simulations since they are representative of projected land pressures in the area. Irrespective of discount rate used, REDD payments could, in principle, induce the participation of the majority of sampled households. This reflects the relatively large but also extensively managed livestock land holdings, the generally low productivity of agricultural and livestock production, and the high carbon content of the Amazon.

Table 5 outlines the measures of agents' welfare $\left(W_{A}\right)$, REDD net income $\left(\pi_{P M}\right)$ and hectares of avoided deforestation $(A D)$. First, under asymmetric information the amount of avoided deforestation is identical across all policy objectives. Irrespective of objective, the policy maker would not buy up all the hectares in this sample of households. With full information, it is neither optimal nor budget compatible for the policy maker with the income maximization objective to buy out all the hectares, even at differing tCER prices. The result is similar for the policy maker pursuing poverty alleviation using a uniform price. It is only optimal for the policy maker with the environmental objective to buy out almost all hectares in our sample at the tCER price with a 5\% discount rate and all hectares at the higher rates. The effect of increased information on opportunity costs is to shift rents from agents

\footnotetext{
8 The carbon content of $110 \mathrm{Mg} \mathrm{C}(\mathrm{t}) /$ ha includes the carbon content of secondary regrowth based on Fearnside's (1996) average biomass figure of $28.5 \mathrm{t} \mathrm{C}$ per hectare for all deforested areas in the Amazon.
} 


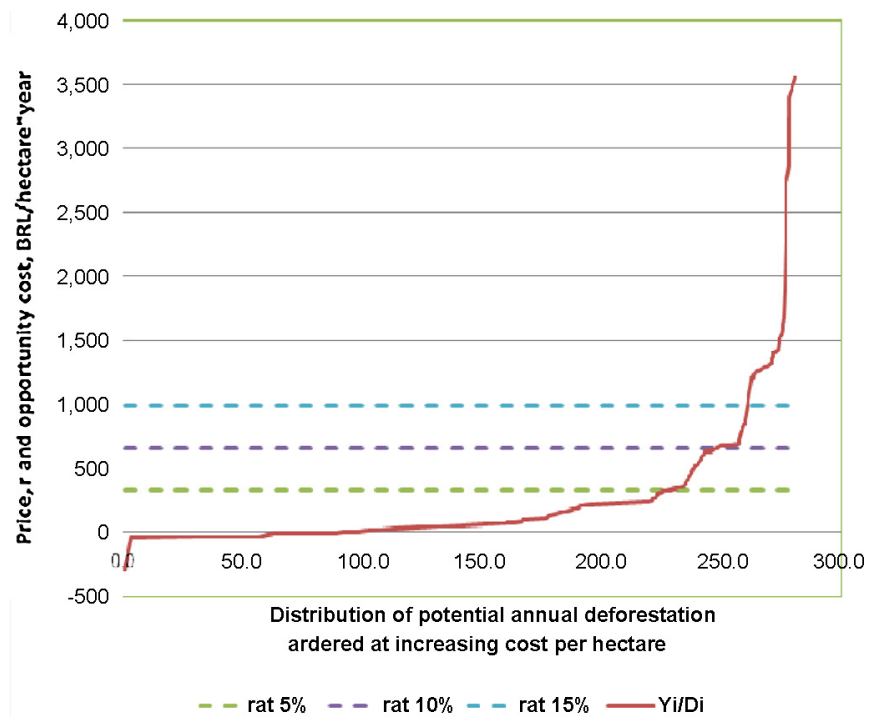

Fig. 5.

\section{Table 5}

Distribution of rents across government and households and the area contracted.

\begin{tabular}{|c|c|c|c|c|c|c|}
\hline Information state & Policy maker & $\rho$ & $\begin{array}{l}\text { tCER cost } \\
\text { BRL/ha }\end{array}$ & $\begin{array}{l}\text { Agents' total welfare gain } \\
W_{A}, \text { BRL/year }\end{array}$ & $\begin{array}{l}\text { REDD net income } \\
\pi_{P M}, \text { BRL/year }\end{array}$ & $\sum_{A D, \text { ha }} D i$ \\
\hline \multirow{9}{*}{ Informed } & \multirow{3}{*}{$\begin{array}{l}\text { Poverty } \\
\text { focus }\end{array}$} & $5 \%$ & 331 & 58,469 & 0 & 218.8 \\
\hline & & $10 \%$ & 663 & 137,231 & 0 & 240.2 \\
\hline & & $15 \%$ & 994 & 222,239 & 0 & 255.8 \\
\hline & \multirow{3}{*}{$\begin{array}{l}\text { Income- } \\
\text { maximizing }\end{array}$} & $5 \%$ & 331 & 0 & 58,469 & 218.8 \\
\hline & & $10 \%$ & 663 & 0 & 137,231 & 240.2 \\
\hline & & $15 \%$ & 994 & 0 & 222,239 & 255.8 \\
\hline & \multirow{3}{*}{$\begin{array}{l}\text { Environmental } \\
\text { focus }\end{array}$} & $5 \%$ & 331 & 0 & 0 & 277.8 \\
\hline & & $10 \%$ & 663 & 0 & 0 & 283.4 (all area) \\
\hline & & $15 \%$ & 994 & 0 & 0 & 283.4 (all area) \\
\hline \multirow{3}{*}{ Uninformed } & Across & $5 \%$ & 331 & 58,469 & 0 & 218.8 \\
\hline & all & $10 \%$ & 663 & 137,231 & 0 & 240.2 \\
\hline & objectives & $15 \%$ & 994 & 222,239 & 0 & 255.8 \\
\hline
\end{tabular}

to the income maximizing policy maker, and from low- to high-cost agents when maximizing the environmental impact of REDD in the area. Both agents' welfare and the amount of hectares enrolled in the REDD scheme remain unchanged when poverty alleviation is the policy focus.

\section{Discussion and conclusion}

In this paper, we develop a simple incentive payments framework for investigating the impacts of improving information about agents' opportunity costs on agents' welfare and the amount of deforestation avoided under differing policy objectives. With growing interest from policy makers and practitioners in policies for Reducing Emissions from Deforestation and Degradation (REDD), we focus on the claim that improving information could lead to increased efficiency. First, an incentive payment is offered by a policy maker in a REDD host country conditional on deforestation agents not deforesting. Second, the carbon services supplied from avoided deforestation may be sold by the host country either on an international carbon market (in the form of carbon credits) or to a fund, at a fixed price. We consider two settings: asymmetric and full information about individual agents' opportunity costs 
and their deforestation levels. In both, the distribution of opportunity costs and BAU deforestation are known to the policy maker.

Reducing the informational setting to two extremes is, we acknowledge, a likely over-simplification of reality in most cases. Yet, we found this to be the clearest way of demonstrating how improved information might influence the environmental and distributional impacts of REDD payments. It also allows us to explore how these impacts vary depending on the objective of the policy maker implementing the payments scheme. We examine three different objectives: maximizing income, maximizing avoided deforestation, and poverty alleviation. The last focuses on the welfare of those directly affected by the scheme.

If the policy maker is income maximizing, improving information about individual opportunity costs enables it to capture the surplus from REDD. This leaves agents at their BAU income levels without increasing the amount of avoided deforestation. Improving information increases the quantity of forest conserved only if the policy maker aims to maximize avoided deforestation within the targeted area. As illustrated with the simulations performed using household data collected in Brazil, it uses the information on opportunity costs to generate profit on low-cost agents thus paying them less than the international price. This profit is then used to retribute agents with larger opportunity costs. We note, however, that by paying these agents more than the international price such payments could be construed as inefficient. Yet the net effect aggregated across all deforestation agents is more deforestation avoided for a given price. It also leaves agents at their BAU income levels.

For the policy maker pursuing the objective of poverty alleviation among agents enrolled in the REDD scheme, improving information may have no real environmental impact. This is particularly likely to be the case should the policy maker decide to adopt a uniform payment in order to transfer rents to agents. Of the three policy objectives, poverty alleviation has the greatest impact in terms of welfare improvements for the rural poor. In this case, the policy maker pays as much as possible to the agents. Irrespective of whether it sets a uniform or non-uniform price across agents, all income is distributed among agents. The amount of deforestation avoided will be at least the same as for the income-maximizing policy maker. Greater amounts are possible if transfers to higher-cost agents are given sufficient weight. Given the demands of stakeholders in the REDD policy debate to improve the well being of (often poor) forest dwellers, these are important insights.

We acknowledge that our typology of policy makers simplifies often complex decision-making processes. Such processes remain essentially unobservable to international sources. Yet important differences in outcomes emerge, particularly if actual policy objectives are different from stated ones. Tropical forest policy making is often characterized by patronage politics and the presence of powerful interest groups close to national policy makers (e.g. see Palmer, 2005; Amacher, 2006). This essentially obscures the true motivations of policy makers (Mayers and Bass, 1998). Indeed, the recent finding that government officials in Liberia were bribed by carbon investors to secure carbon rights to a forest concession at below-market values suggests that corruption is already playing an unwelcome role in REDD policy (Financial Times, 2010). A rent-seeking policy maker is most likely to resemble the income-maximizing policy maker in our framework. In this case, moving to a full information setting could potentially exacerbate the problem.

Our model assumes an international price for forest carbon sinks that would otherwise be deforested. Funding for REDD could be obtained by the host country either through an international (regulated) carbon market and/or (voluntary) fund. Where the policy maker's objective can be discerned truthfully, at least to some extent, the source of international funding becomes relevant. An international market, like any market, will be indifferent to the objective of the policy maker and hence, will not discriminate accordingly. A fund, on the other hand, may have the ability to discriminate among types of policy maker. For example, it could choose to avoid REDD host governments with a record of corruption or focus on those with well-governed environmental agencies. With this flexibility, a fund-based financing mechanism may be better placed than a market to choose among competing policy objectives particularly if REDD is not to focus on maximizing forest carbon services alone.

In addition to the informational setting, we remark on other simplifying features of our model, all of which could be subject to further research. First, we ignored all possible types of transaction costs. Such costs may reduce the incentives for agents to participate (Anthon et al., 2007a). There are also likely to be costs associated with obtaining information on agents' opportunity costs. Where these are 
relatively low, policy makers aiming to maximize the amount of deforestation avoided or their own income may still find it efficient to obtain such information. The policy maker with a poverty alleviation aim, on the other hand, may have little incentive to do so. Yet, an incentive could be created if it has certain preferences for how rents might be distributed, i.e. leading to the adoption of differentiated payments instead of a uniform price across agents.

If obtaining information about opportunity costs is relevant, the question that follows is knowing when reducing private information might be worthwhile. As our analysis shows, the answer depends, to some degree, first on the policy maker and its primary policy objective and second, on the distribution of costs and carbon outputs across the relevant sample of agents. Where payments are made by a social planner, information rent is a transfer and not a welfare economic cost. ${ }^{9}$ It may therefore have little interest in reducing informational rents. If, however, the policy maker is rent seeking or a private entity interested in maximizing profits it may seek to reduce informational rents. An environmental agency focused on the quantitative output of its policies might be more sensitive to these rents and could seek to reduce them more than say a social planner (see Anthon et al., 2007b).

Regarding the distribution of opportunity costs, where these vary greatly over the range of carbon output then informational rents are likely to be large. Hence, ceteris paribus, they are more likely to be worth reducing. If, on the other hand, there is relatively little variation then there will be relatively few rents. In our Brazilian case, where the policy maker only seeks to enrol some portion of the land available our data suggest relatively little variation in opportunity costs. Rents will therefore be modest and it may not be worthwhile reducing these given the costs involved. But in cases where there is large variation in opportunity costs and where the policy maker either seeks to maximize income or the quantity of avoided deforestation, it may apply one of the following three methods (see also Ferraro, 2008). First, screening contracts can be implemented to give landowners incentives to selfselect. Second, reverse auctions create a market in which potential participants compete with each other, which, under certain conditions (the absence of collusion, mainly), can create an incentive to reveal true opportunity costs. Finally, it could implement second-order discrimination by identifying information strongly correlated with opportunity costs. The latter could be inferred from information gathered from surveys similar to the one we undertook in Brazil. Ideally these data have to be observable and costly to fake in order to avoid adverse selection.

Our model implicitly assumes secure land tenure along with clearly defined and -enforced property rights to the benefits of forest use. These are generally considered to be a prerequisite for the effective implementation of a REDD payments scheme. In reality, such conditions are unlikely to be found across much of the tropics. Poorly defined and/or -enforced property rights will almost certainly undermine the basis for legitimate claims to the benefits from any kind of payments scheme. If a policy maker has difficulties determining which agent has de facto property rights then this will clearly reduce the set of agents eligible for contracting into the REDD scheme. But where agents can contract into the scheme, weak enforcement implies problems of contract compliance (see MacKenzie et al., 2011). Given such uncertainty, we would expect the rent from REDD to be rather less than in situations where property rights are reasonably well defined and enforced. In turn, the policy maker would have fewer rents to extract from a REDD scheme.

Finally, our framework assumes that policy makers' objectives are confined to deforestation agents and their forest areas only (albeit with varying weight). Clearly, policy makers will have other, legitimate concerns, also in terms of environmental and development objectives. For those with a broader climate strategy, for example, carbon leakage is a major concern. In our model, we do not consider the potential for agents to conserve forests on their land while choosing to deforest elsewhere. This relates to the problems of weak property rights, which could increase the risk of leakage. A policy maker looking to maximize the area of deforestation avoided is perhaps the one most likely to pay attention to this issue.

\footnotetext{
${ }^{9}$ If payments are funded by public funds, transfers may involve some fractional costs due to distortion (Anthon et al., 2007a), but we ignore these here.
} 


\section{Acknowledgements}

The research leading to these results has received funding from the European Union's Seventh Framework Program (FP7/2007-2013) under grant agreement NEWFOREX (no. 243950). Riyong Kim Bakkegaard and Bo Jellesmark Thorsen acknowledges support and funding from the Danish National Science Foundation. Field work was also supported by Fundacão Amazonas Sustentavel, CIFORBrazil, CIFOR GCS, CIFOR, Torben and Alice Frimodts Fond, the WWF REDD project, Stiftelsen Løvstrupgaard, Landbrugets Studie Fond, Jordbrugs Akademikerne. Thanks also to field assistants Denise Reis dos Nascimento, Simone Santos, Mario Acuna, Ivan Zarros, and Patricia Gallo, Kaline Rossi do Nascimento. This paper was presented at the EAERE annual conference (Rome, Italy, June 2011) and at a research seminar at the University of Copenhagen (Denmark, October 2011) and the University of Paris Ouest (France, February 2012). Finally we thank Richard Horan and two anonymous reviewers for useful comments.

\section{References}

Amacher, G.S., 2006. Corruption: a challenge for economists interested in forest policy design. Journal of Forest Economics 12 (2), 85-89.

Angelsen, A., 2008. REDD models and baselines. International Forestry Review 10 (3, sp. iss. SI), 465-475, International Workshop on the International Regime - Avoided Deforestation and the Evolution of Public and Private Policies Towards Forests in Developing Countries, Paris, France, November 21-23, 2007.

Angelsen, A., 2010. Policies for reduced deforestation and their impact on agricultural production? Proceedings of the National Academy of Sciences of the United States of America 107 (46), 19639-19644.

Anthon, S., Bogetoft, P., Thorsen, B., 2007a. Socially optimal procurement with tight budgets and rationing? Journal of Public Economics 91 (7-8), 1625-1642.

Anthon, S., Bogetoft, P., Thorsen, B.J., 2007b. A bureaucrat's procurement strategy: budget constraints and rationing? Annals of Public and Cooperative Economics 78 (2), 221-244.

Arguedas, C., Soest, D., 2011. Optimal conservation programs, asymmetric information and the role of fixed costs. Environmental \& Resource Economics 50 (2), 305-323.

Asquith, N.M., Vargas, M.T., Wunder, S., 2008. Selling two environmental services: in-kind payments for bird habitat and watershed protection in los negros, bolivia. Ecological Economics 65 (4), 675-684, Payments for Environmental Services in Developing and Developed Countries.

Bayon, R., Hawn, A., Hamilton, K., 2012. Voluntary Carbon Markets: An International Business Guide to What They Are and How They Work. Environmental Markets Insight Series. Taylor \& Francis, London, UK.

Börner, J., Wunder, S., 2008. Paying for avoided deforestation in the Brazilian Amazon: from cost assessment to scheme design. International Forestry Review 10 (3), 496-511+.

Börner, J., Wunder, S., Wertz-Kanounnikoff, S., Tito, M.R., Pereira, L., Nascimento, N., 2010. Direct conservation payments in the Brazilian Amazon: scope and equity implications. Ecological Economics 69 (6), 1272-1282, Special Section - Payments for Environmental Services: Reconciling Theory and Practice.

Brown, D., Seymour, F., Peskett, L., 2008. How do we achieve REDD co-benefits and avoid doing harm? In: Angelsen, A.E. (Ed.), Moving Ahead with REDD: Issues, Options and Implications. Centre for International Forestry Research (CIFOR).

Bulte, E.H., Lipper, L., Stringer, R., Zilberman, D., 2008. Payments for ecosystem services and poverty reduction: concepts, issues, and empirical perspectives. Environment and Development Economics 13 (03), 245-254.

Dutschke, M., Wong, J.L.P., Rumberg, M., 2004. Value and risks of expiring carbon credits from CDM afforestation and reforestation. Climate Policy 5, 109-125.

Eliasch, J., 2008. Climate Change: Financing Global Forests: The Eliasch Review. Earthscan, London/Sterling, VA.

Engel, S., Palmer, C., 2009. Avoided Deforestation: Prospects for Mitigating Climate Change. Routledge, New York, NY.

Fearnside, P.M., 1996. Amazonian deforestation and global warming: carbon stocks in vegetation replacing Brazil's Amazon forest? Forest Ecology and Management 80 (1-3), 21-34.

Ferraro, P., Simpson, D., 2002. The cost-effectiveness of conservation performance payments? Land Economics 78 (03), 339-353.

Ferraro, P.J., 2008. Asymmetric information and contract design for payments for environmental services? Ecological Economics 65 (4), 810-821.

Ferraro, P.J., Kiss, A., 2002. Direct payments to conserve biodiversity? Science 298 (5599), 1718-1719.

FinancialTimes, 2010, 4th June. Probe as carbon deal hit by bribe accusations. Financial Times http://www.ft.com/ cms/s/0/61b50aa4-6f71-11df-9f43-00144feabdc0.html

Groom, B., Palmer, C., 2010. Cost-effective provision of environmental services: the role of relaxing market constraints? Environment and Development Economics 15 (02), 219-240.

Groom, B., Palmer, C., 2012. REDD+and rural livelihoods. Biological Conservation 154 (0), 42-52, REDD+and conservation.

Horan, R.D., Claassen, R., 2007. Targeting green payments under a budget constraint? Land Economics 83 (3), 319-330.

IBGE, 1997. Diagnostico ambiental da amazonia legal. Rio de Janeiro, RJ, Brasil.

IPCC, 2007. Fourth assessment report (ipcc ar4). Technical report. Intergovernmental Panel on Climate Change, Geneva.

Jack, B.K., Leimona, B., Ferraro, P.J., 2009. A revealed preference approach to estimating supply curves for ecosystem services: use of auctions to set payments for soil erosion control in Indonesia. Conservation Biology 23 (2), 359-367. 
Leplay, S., Busch, J., Delacote, P., Thoyer, S., 2011. Implementation of national and international REDD mechanism under alternative payments for environmental services: theory and illustration from Sumatra. Working papers. LAMETA, University of Montpellier.

MacKenzie, I.A., Ohndorf, M., Palmer, C., 2011. Enforcement-proof contracts with moral hazard in precaution: ensuring 'permanence' in carbon sequestration. Oxford Economic Papers.

May, P., Milikan, B., Gebara, M., 2011. The Context of REDD+in Brazil: Drivers, Agents and Institutions. Occasional Paper 55, 2nd ed. CIFOR, Bogor, Indonesia.

Mayers, J., Bass, S., 1998. In: Goldsmith, et al. (Eds.), Tropical Rain Forest: A Wider Perspective. The role of policy and institutions. Springer, New York, USA, pp. 269-302.

Muller, J., Albers, H.J., 2004. Enforcement, payments, and development projects near protected areas: how the market setting determines what works where. Resource and Energy Economics 26 (2), 185-204.

Muñoz-Piña, C., Guevara, A., Torres, J.M., Braña, J., 2008. Paying for the hydrological services of Mexico's forests: analysis, negotiations and results. Ecological Economics 65 (4), 725-736.

Neeff, T., Ascui, F., 2009. Lessons from carbon markets for designing an effective REDD architecture? Climate Policy 9 (3), 306-315.

Pagiola, S. and Bosquet, B. (2009). Estimating the costs of REDD at the country level. MPRA Paper 13726, University Library of Munich, Germany.

Palmer, C., 2005. The nature of corruption in forest management? World Economics 6 (2), 1-10.

Palmer, C., 2011. Property rights and liability for deforestation under REDD+: implications for 'permanence' in policy design? Ecological Economics 70 (4), 571-576.

Pattanayak, S., Wunder, S., Ferraro, P.J., 2010. Show me the money: do payments supply ecosystem services in developing countries? Review of Environmental Economics Policy 04 (02).

Rawls, J., 1971. A Theory of Justice. Harvard University Press, Cambridge, Massachusetts, USA.

SDS, FAS, CEUC, 2010. Plano de gestão da reserva de desenvolvimento sustentavel do juma. Volume 1 e 2 . Série Técnica Planos de Gestão. Março 2010. Novo Aripuana, Amazonas.

Simonet, G., Bouculat, G., Oliveira, A., 2012. Forest Carbon: Tackling Externalities. Information et Debates 17. Chaire d'économie du Climat, Paris, France.

Smith, R., 1995. The conservation reserve program as a least-cost land retirement mechanism. American Journal of Agricultural Economics 77, 93-105.

Soares-Filho, B.S., Nepstad, D.C., Curran, L.M., Cerqueira, G.C., Garcia, R.A., Ramos, C.A., Voll, E., McDonald, A., Lefebvre, P., Schlesinger, P., 2006. Modelling conservation in the Amazon basin? Nature 440 (7083), 520-523.

Stern, N., 2007. The Economics of Climate Change: The Stern Review. Cambridge University Press, Cambridge, UK.

Stoneham, G., Chaudhri, V.H.A., Strappazzon, L., 2003. Auctions for conservation contracts: an empirical examination of victoria's Bushtender trial? Australian Journal of Agricultural and Resource Economics 47 (004), 477-500.

Sunderlin, W., Larson, A., Cronkleton, P., 2009. Chapter 11: forest tenure rights and REDD-: from inertia to policy solutions. In: Angelsen, A., Brockhaus, M., Kanninen, M., Sills, E., Sunderlin, W., Wertz-Kanounnikoff, S.E. (Eds.), Realising REDD+: National Strategy and Policy Options. Centre for International Forestry Research (CIFOR).

Taiyab, N., 2006. Exploring the Market for Voluntary Carbon Offsets, Markets for environmental services. International Institute for Environment and Development.

UNREDD, 2009. Newsletter 3, October 2009. Available at: http://www.un-redd.org/Newsletter3promotingcobenefits/tabid/ 2041/language/en-US/Default.aspx

van der Werf, G.R., Morton, D.C., DeFries, R.S., Olivier, J.G.J., Kasibhatla, P.S., Jackson, R.B., Collatz, G.J., Randerson, J.T., 2009. CO emissions from forest loss? Nature Geoscience 2 (11), 737-738.

Vosti, S., Witcover, J., Carpentier, C., 2002. Agricultural intensification by smallholders in the western Brazilian Amazon. From deforestation to sustainable land use. Research Report 130. International Food Policy Research Institute, Washington. DC.

Wu, J., Babcock, B.A., 1995. Optimal design of a voluntary green payment program under asymmetric information. Journal of Agricultural and Resource Economics 20 (02).

Wu, J., Babcock, B.A., 1996. Contract design for the purchase of environmental goods from agriculture? American Journal of Agricultural Economics 78 (4), 935-945.

Wu, J., Zilberman, D., Babcock, B.A., 2001. Environmental and distributional impacts of conservation targeting strategies? Journal of Environmental Economics and Management 41 (3), 333-350.

Wunder, S., 2005. Payments for environmental services: some nuts and bolts. CIFOR Occasional Paper No. 42. Center for International Forestry Research, Bogor.

Wunder, S., Engel, S., Pagiola, S., 2008. Taking stock: a comparative analysis of payments for environmental services programs in developed and developing countries? Ecological Economics 65 (4), 834-852. 